\title{
Separation and Identification of New Phytocomponents in Methanolic Extract of Leaves of Hairknot Plant (Pergularia daemia) by GC-MS Analysis
}

\author{
PALLAVI A ${ }^{1}$, NAGABABU ${ }^{2}$, HARI BABU $B^{3}$ and BRAHMAJI RAO P. ${ }^{1 *}$ \\ 'Department of Environmental Science, Acharya Nagarjuna University, NNagar-522 510, \\ Andhra Pradesh, India. \\ ${ }^{2}$ Department of Botany \& Microbiology, Acharya Nagarjuna University, NNagar-522 510, \\ Andhra Pradesh, India. \\ ${ }^{3}$ Department of Chemistry, Acharya Nagarjuna University, NNagar-522 510, \\ Andhra Pradesh, India. \\ ${ }^{*}$ Corresponding author E-mail: drbrahmajirao@gmail.com; dr.b.haribabu@gmail.com \\ http://dx.doi.org/10.13005/ojc/360631
}

(Received: September 30, 2020; Accepted: November 01, 2020)

\begin{abstract}
The investigation was designed to trigger the complete chemical constituents present in the methanolic extract of leaves of hair knot plant; botanically known as Pergularia daemia belongs to the family of the Asclepiadaceae one of the endemic plants of Andhra Pradesh, India by Agilent Technologies Gas Chromatography-Mass Spectrometry and components were well separated on HP-5 MS capillary column consisting of stationary phase of $5 \%$ phenyl $95 \%$ methylpolysiloxane. The resulted compounds were appropriate to the NIST (National Institute of Standards and Technology) library and the study indicated the presence of different phytochemical compounds. A total of 51 compounds were recognized in the methanolic extract of Pergularia daemia leaves. Further, five new compounds were separated and four of biological importance viz. Pentadecane, Tetratriacontane, Dibutyl phthalate and Squalene were identified. The results of the importance of biologically active phytochemicals in the study recommend, P. daemiaas as a plant of phytopharmaceutical reputation.
\end{abstract}

Keywords: Bioactive compounds, Phytochemicals, GC-MS, Pergularia daemia, Asclepiadaceae.

\section{INTRODUCTION}

The use of plants in several countries as a major source of medicines is hereditary and has an important element of the health care system. India has a lengthy history and strong base for the traditional herbal medicinal system and is suitably called as the botanical garden of the world ${ }^{1}$.
Biological studies are used to extract wide medicinal properties from plants ${ }^{2}$.

As synthetic drugs which are consumed by human beings may have various side effects and may lead to serious health complications. So, herbal medicine was the life saving drug with fewer side effects and minimum cost effort. Generally,

This is an Open Access article licensed under a Creative Commons license: Attribution 4.0 International (CC- BY). Published by Oriental Scientific Publishing Company @ 2018

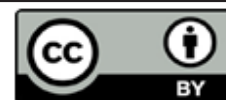


the progress of herbal medicine was carried by the preliminary screening of the constituents in plant sample extracts. The plant chemicals that are not necessary for growth and development but have the properties to protect or prevent diseases are called phytochemicals. The plant produces these chemicals to protect them and they have the ability to treat human diseases also $^{3}$. There are many phytochemicals, which have their own pharmacological importance ${ }^{4}$. The plant Pergularia daemia is known as "Dushtupatige" in Telugu and "Uttaravaruni" in Sanskrit. Pergularia daemia dried leaf is effectively used in treating asthma, dysmenorrheal, rheumatic fever, bronchitis, amenorrhea, and wounds, etc. ${ }^{5}$. It has pharmacological importance like anti-microbial, anti-fungal properties, anti-rheumatic, antiarthritic, anti-inflammatory, anti-proliferative, and a good anti-oxidant ${ }^{6-9}$. The previous analysis only reported for potent snack venom potency of four constituents B-sitosterol, B-amyrin, alpha-amyrin, and Lupeol from leaves of Pergularia daemia by GC-MS method ${ }^{10}$. The study on ethanolic extract of leaves reports the existence of methyl Ester pentadecoinic acid, 14-methyl-methyl Esterethyl 9-12-15-Octodecotrionate, hexadecanoic acid, and 4-4 chlorobenzyl-1-cyclohexoxyl l-5-tosylamino-1, $\mathrm{H}-123$ and also B-sitosterol, lupeol, lupeol acetate, alpha-beta amyrin and its acetate in entire plant and flower. While lupeol-3 Betatranscrotonate and oleanolic acid acetate in dried entire plant ${ }^{11}$. These reports are helpful for our investigation to go for a complete analysis.

The medicinal assets of P.daemia may be due to the occurrence of its phytochemical ingredients which is not yet explored thoroughly in the Andhra Pradesh region of India except other species in the family ${ }^{12}$. Moreover, the preliminary studies ${ }^{13,14}$ on the phytochemicals of $P$. daemia also encouraged for the present study. In the present investigation, the Gas Chromatographic-Mass Spectrometric Analysis (GCMS) is attempted for the methanol extract of dried leaves for the exploration of most phytochemicals in a quantitative manner. The plant possesses various medicinal properties as per the report on Indian medicinal plants ${ }^{15}$. So the motto of our study is to identify the most phytocompounds in the methanolic extract of Pergularia daemia leaves along with their concentrations by GC-MS analysis.

\section{EXPERIMENTAL}

\section{Plant Material Collection}

The Pergularia daemia plant leaves were collected at Nallamalla forest, Prakasam district, Andhra Pradesh in August. The plant was properly identified by a senior Botanist Prof. Dr. Vatsavaya S. Raju, Department of Botany, Kakatiya University, Telangana-506 009.

\section{Preparation of extracts}

The air dried powder of leaf was extracted in a soxhlet extractor with methanol and was air dried in a hot air oven at 40 degrees Celsius then the material was softened by soaking (maceration) in hot water with occasional steering for $16 \mathrm{~h}$ and water extract was filtered. Finally, the solvent extract was evaporated to remove the final traces of the concerned solvent. The extract recovery in the solvent was expressed as a percent of the plant sample dry matter. This extract was utilized for the GC-MS examination to identify the components.

\section{GC-MS (Gas Chromatography-Mass Spectrometry) analysis}

To the sample, $500 \mu \mathrm{L}$ of $\mathrm{n}$-butane was added and vortex for $1 \mathrm{~min}$ and poured into a screw-capped GC glass vial. Next, the sample was exposed to GC-MS analysis for metabolic data at $70 \mathrm{eV}$ with an electron impact ionization $\left(\mathrm{El}^{+}\right)$ source. The source is GC 7890 and MS of $5977 \mathrm{~N}$, Agilent Technologies, palo Alto, CA, USA. The capillary HP-5 MS column with dimensions $30 \mathrm{mX}$ $250 \mu$ mi.d. $X 0.25 \mu \mathrm{m}$ film thickness) consisting of $5 \%$ phenyl $95 \%$ methylpolysiloxane as stationary phase in splitless mode was used for analysis. The investigation was performed by injecting an aliquot of $1 \mu \mathrm{L}$ of the extract into the injection port at $25^{\circ} \mathrm{C}$ temperature by the use of Helium as flow gas with an overall flow rate of $1 \mathrm{~mL} /$ minute. In this study the oven temperature was programmed as-initial oven temp set at $50^{\circ} \mathrm{C}$ for $2 \mathrm{~min}$ then elevated to $150^{\circ} \mathrm{C}$ at a rate of $50^{\circ} \mathrm{C} / \mathrm{min}$ and maintained for $2 \mathrm{~min}$ then finally raised to $300^{\circ} \mathrm{C}$ at a rate of $15^{\circ} \mathrm{C} / \mathrm{min}$, where it was held for 20 minute.

\section{Data Pre-Processing}

The individual components from the peaks obtained in GC-MS spectra were recognized by relating their mass spectra with the spectra of 
known compounds stored in the spectral catalog of NIST library (version 8.0). The baseline correction, smoothing, noise reduction and integration were done before the identification.

\section{RESULTS AND DISCUSSION}

GC-MS is one of the leading techniques to recognize various constituents of crude extracts like branched chain, long chain, hydrocarbons, amides, vitamins, acids, alcohols, esters, etc. So, in this study GC-MS analysis was selected to identify the components of based on retention time, peak area, molecular formula, molecular weight and nature of compounds were also analyzed from NIST data. The separated components with their proper Retention times (RT), peak area in percentage, molecular formula, and molecular weight (MW) obtained as per GC-MS analysis Fig. 1 of the methanol extract of Pergularia daemia leaves were presented Table 1.

Table 1: Compounds recognized in methanolic extract of P. daemia leaves in GC-MS

\begin{tabular}{|c|c|c|c|c|c|c|}
\hline S.No. & $\begin{array}{l}\text { Retention } \\
\text { time }\end{array}$ & $\begin{array}{c}\text { Peak } \\
\text { area \% }\end{array}$ & $\begin{array}{l}\text { Name of the } \\
\text { compound }\end{array}$ & $\begin{array}{l}\text { Molecular } \\
\text { Formula }\end{array}$ & $\begin{array}{l}\text { Molecular } \\
\text { Weight }\end{array}$ & $\begin{array}{l}\text { Nature of the } \\
\text { compound }\end{array}$ \\
\hline 1 & 3.79 & 0.31 & 1-Dodecene & & 168 & Alkene \\
\hline 2 & 4.19 & 0.09 & Trans-alpha-Bergamotene, & & 204 & $\begin{array}{l}\text { Bicyclic } \\
\text { compound }\end{array}$ \\
\hline 3 & 4.71 & 0.16 & Pentadecane & & 212 & Alkane \\
\hline 4 & 5.57 & 0.88 & Dichloroacetic acid, 4-hexadecylester & & 353.4 & Acid ester \\
\hline 5 & 6.85 & 0.17 & Tetratriacontane & & 478 & Alkane \\
\hline 6 & 7.29 & 0.04 & Heptacosane & & 380 & Alkane \\
\hline 7 & 7.60 & 1.21 & 1- octadecene & & 252 & Alkene \\
\hline 8 & 8.12 & 0.10 & 6-Octen-1-ol, 3,7-dimethyl-,(R)- & & 156 & Terpenoids \\
\hline 9 & 8.69 & 0.12 & Nonadecane & & 268 & Alkane \\
\hline 10 & 9.11 & 0.18 & Dibutyl phthalate & & 166 & $\begin{array}{c}\text { Aromaticcarboxylic } \\
\text { acid ester }\end{array}$ \\
\hline 11 & 9.58 & 1.68 & E-15-Heptadecenal & & 252 & Fatty aldehyde \\
\hline 12 & 10.59 & 0.42 & Heneicosane & & 296 & Acyclic alkanes \\
\hline 13 & 11.07 & 0.24 & Ethyl Oleate & & 310 & Fatty acid Ester \\
\hline 14 & 11.42 & 1.76 & 1-Docosene & & 308 & Alkene \\
\hline 15 & 12.36 & 2.18 & 1-lodo-2-methylundecane & & 296 & lodoalkane \\
\hline 16 & 13.14 & 1.74 & Dichloroacetic acid, heptadecyl ester & & 367 & Acid ester \\
\hline 17 & 14.03 & 8.46 & Pentacosane & & 352 & Alkane \\
\hline 18 & 14.74 & 2.36 & Hexacosane & & 336 & Alkane \\
\hline 19 & 15.57 & 15.89 & Heptacosane & & 380 & Alkane \\
\hline 20 & 16.28 & 4.25 & Squalene & & 410 & Triterpene \\
\hline 21 & 16.92 & 7.87 & Nonacosane & & 408 & Alkane \\
\hline 22 & 17.55 & 3.13 & Tridecane, 7-hexyl- & & 268 & Alkane \\
\hline 23 & 18.35 & 3.17 & Hentriacontane & & 436 & Alkane \\
\hline 24 & 19.9 & 2.50 & 9-Hexacosene & & 364 & alkene \\
\hline 25 & 19.48 & 1.44 & (Z)-14-Tricosenyl Formate & & 366 & ester \\
\hline 26 & 20.19 & 1.71 & Z-12-Pentacosene & & 350 & Alkene \\
\hline 27 & 20.48 & 1.49 & 8-Hexadecenal,14-methyl-(z)- & & 252 & aldehyde \\
\hline 28 & 21.44 & 7.74 & 1-Hexacosanol & & 382 & alcohol \\
\hline 29 & 21.84 & 1.47 & Beta-Sitosterol acetate & & 396 & Steroid \\
\hline 30 & 22.72 & 1.82 & 1-Docosanethiol & & 342 & Fatty Thioalcohol \\
\hline 31 & 23.42 & 2.49 & Phytol & & 296 & Terpenoid \\
\hline 32 & 24.33 & 2.21 & Cyclotriacontane & & 420 & Cycloalkane \\
\hline 33 & 25.06 & 0.97 & Tricosane & & 324 & Alkane \\
\hline 34 & 25.99 & 1.46 & Heptanoic acid, phenyl methyl ester & & 130 & Ester \\
\hline 35 & 26.72 & 1.87 & Cyclohexane, 1-(1,5-dimethylhexyl)-4-(4-methylpentyl)- & & 84 & Alkane \\
\hline 36 & 27.19 & 1.03 & 1,19-Eicosadiene & & 278 & Terminal alkene \\
\hline 37 & 27.77 & 0.64 & Octanoic acid, octadecyl ester & & 396 & Ester \\
\hline 38 & 28.30 & 2.56 & Undecanoic acid, phenyl methyl ester & & 276 & Ester \\
\hline 39 & 29.38 & 0.52 & 2-methyl- 2-docosene & & 322 & Alkene \\
\hline 40 & 29.63 & 0.43 & Propanamide, N-(4-methoxyphenyl )-2,2,3,3,3-pentafluoro- & $\mathrm{C}_{10} \mathrm{H}$ & 193 & Amide \\
\hline 41 & 29.97 & 0.48 & Androst-5,7-dien-3-ol-17-one, acetate & & 360 & Steroid \\
\hline 42 & 30.50 & 0.85 & 2-Propenamide,3-phenyl-N,N- bis(phenylmethyl)- & $\mathrm{H}_{21}^{32} \mathrm{NO}$ & 327 & Amide \\
\hline 43 & 31.05 & 1.57 & Butanoic acid, 2-methyl- & ${ }_{10}^{21} \mathrm{O}_{2}$ & 88 & Fatty acid \\
\hline 44 & 31.90 & 0.39 & 1,2-Benzenediol, 3,5-bis(1,1-dimethylethyl)- & ${ }_{22} \mathrm{O}_{2}^{2}$ & 222 & Catechol \\
\hline 45 & 32.25 & 0.54 & Pyridine-3-carboxamide,Oxime, N-(2-trifluoromethylphenyl)- & $\mathrm{F}_{3} \mathrm{~N}_{3}^{2} \mathrm{O}$ & & Vitamin \\
\hline 46 & 32.65 & 0.68 & Octadecane, 1-(ethenyloxy)- & & 296 & Ether \\
\hline 47 & 33.00 & 0.60 & 2,6-methano-3-benzazocin-8-ol & $\mathrm{C}_{17} \mathrm{H}_{23} \mathrm{NO}$ & 257 & Phenolic \\
\hline 48 & 33.58 & 1.09 & Octanoic acid, Hexadecyl ester & $\mathrm{C}_{24} \mathrm{H}_{48} \mathrm{O}_{2}$ & 368 & Esters \\
\hline 49 & 34.42 & 2.61 & Dodecanoic acid, phenylmethyl ester & $\mathrm{C}_{10}^{24} \mathrm{H}_{30} \mathrm{O}_{2}$ & 290 & Ester \\
\hline 50 & 36.21 & 1.82 & 2-Benzo $[1,3]$ dioxol-5-yl-8-methoxy-3-nitro-2H-chromene & & 327 & chromene \\
\hline 51 & 36.70 & 0.61 & Androst-5-ene-3,17-diol, 4,4-di... & $\mathrm{C}_{19} \mathrm{H}_{26} \mathrm{O}_{2}$ & 286 & Steroid \\
\hline
\end{tabular}




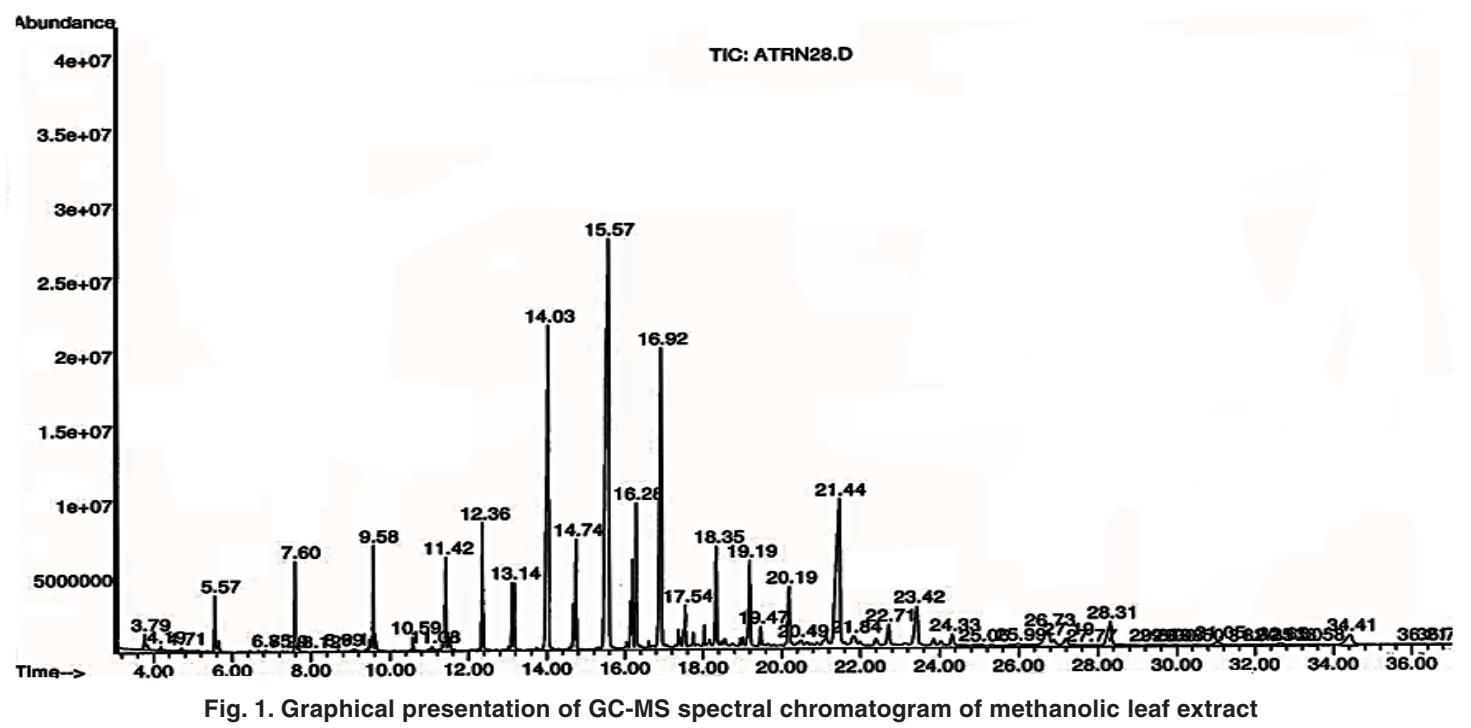

As per the NIST library, the leaf extract contains several hydrocarbons such as alkanes, alkenes; fatty acids, alcohols, esters, ethers, amides, steroids, terpenoids, triterpenes, vitamin, chromenes and various phenolic compounds. Further as per the knowledge of the author on the reports of $P$. daemia, the compounds Pentadecane, Tetratriacontane, Dibutyl phthalate, 1-(ethenyloxy)Octadecane and Squalene were not reported in any GC-MS analysis and some are known to be biologically important Table 2 .

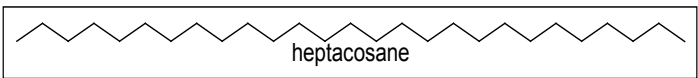

Fig. 2. Structure of the major compound identified in GC-MS of leaf extract

Further, the mass spectrum of the major component Fig. 2. Separated at a retention time of 15.57 min with peak area of $15.89 \%$ was also studied and reported in Fig. 3. After heptacosane the compound pentacosane was separated as major component at 14.03 with peak area $8.46 \%$.

The identified compounds were of many biological importance, the details of some of the components were presented in Table 2. GC-MS examination of phytochemicals in plants provides the design of the pharmacological importance of that plant. So, this type of study with GC-MS examination is the leading step towards knowing the type of medicinal values in the concerned medicinal plants and helpful for detailed study.

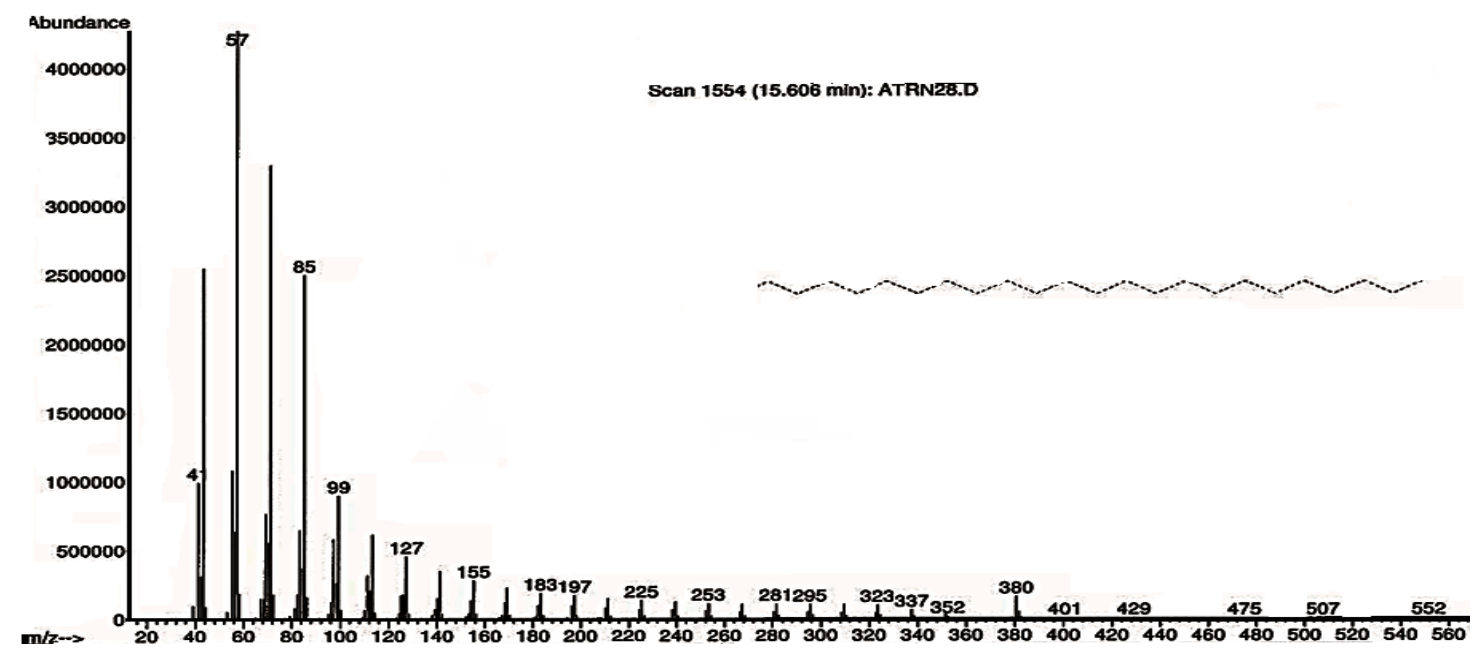

Fig. 3. Mass spectrum of the major compound identified in GC-MS of leaf extract 
Table 2: Bioactivities of some phytocompounds identified in methanolic extract of $P$.daemia leaves by GC-MS

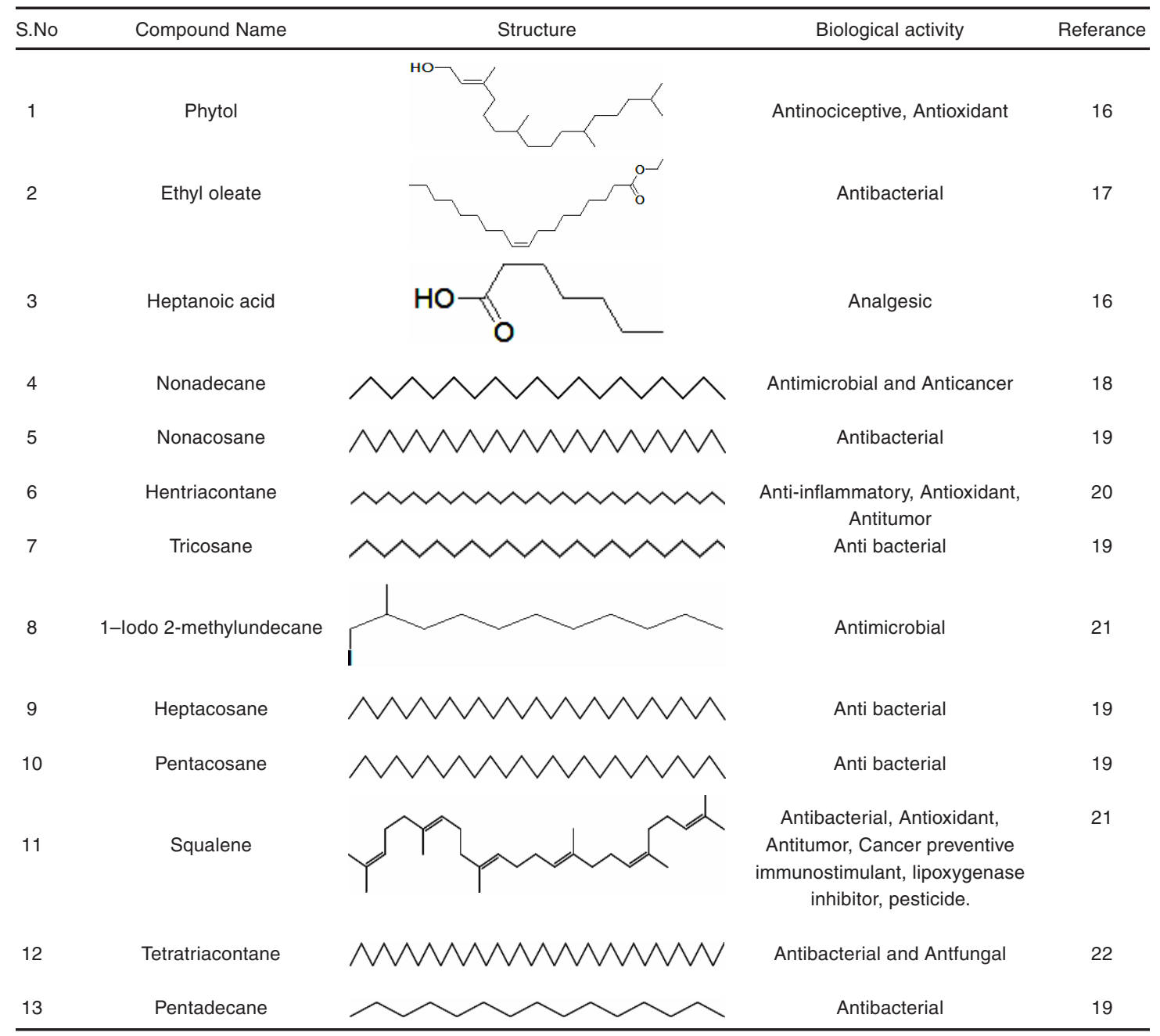

\section{CONCLUSION}

A total of 51 components were identified in the complete GC-MS examination of P.damea leaves extract. The existence of various bioactive compounds reported in this GC-MS analysis for the methanolic extract of leaves of $P$. daemia confirmed the use of leaf extract for various activities by the traditional practitioner. Always isolation of individual phytochemicals and subjecting them to various biological activities will surely give effective results that open a new area of examination of the components and their pharmacological efficacy.
From these results, it could be concluded that "Pergularia daemia" contains various bioactive compounds. Therefore, the plant is recommended as a plant with good phytopharmaceutical rank.

\section{ACKNOWLEDGEMENT}

The authors are thankful to Acharya Nagarjuna University for constant support and encouragement.

\section{Conflict of interest}

The authors declare no conflict of interest.

\section{REFERENCES}

1. Ahmedull, M.; Nayar, M.P. Red data book for Indian plants, Botanical Survey of India. Calcutta., 1999, 4.

2. Rastogi, R.P.; Mehrotra, B.N.; Compendium of Indian medicinal plants., New Delhi,
India, Central Drug Research, Lucknow and NISCAIR., 1979, 2, 521.

3. Dutta, A.; Ghosh, S. J. Am. Pharm. Assoc., 1947, 36, 250-252. https://doi.org/10.1002/ jps.3030360808. 
4. Anjaneyulu, A.S.N.; Raju, D.V.S.N.; Srinivasa Rao, S. Indian. J. Chem., 1998, 37, 318-320.

5. Bhaskar, V.H.; Balakrishnan, N. Int. J. PharmTech. Res., 2009, 1, 1305-1313.

6. Kakrani, H.K.N.; Saluja, A.K. Fitoterapia., 1994, 65, 427-430.

7. Kaushik, J.C.; Sanjay, A.; Tripathi, N.N.; Arya, S. Indian J. Forestry., 2002, 25, 359-361.

8. Lampronti, I.; Saab, A.M.; Gambari. R. Int. J. Oncol., 2006, 29, 989-995.

9. Lee, S.J.; Umano, K.; Shibamoto, T.; Lee, K.G. Food. Chem., 2005, 91, 131-137. https://doi. org/10.1016/j.foodchem.2004.05.056.

10. Raghavamma, S.T.V.; Ramarao, N.; Devala Rao. G. J. Genetic Eng. Biotech., 2016, 14, 211-217. http://dx.doi.org/10.1016/j.jgeb. 2015.11.002.

11. Chandak, R. R.; Dighe, N. S. J. Drug Delivery. Therapeutics., 2019, 9, 809-814. http://dx.doi. org/10.22270/jddt.v9i4-s.3426.

12. Elango, V.; Ambujavalli, L.; AmalaBasker, E.; Sulochana, N. Fitoterapia., 1985, 56, 300-302.

13. Brahmam, P.; Sunita, K.; Babu, B.H. European J. Biomed. Pharma. Sci., 2018, 5, 977-983.
14. Pallavi, A.; Brahmaji Rao, P. Studies in Indian Place Names., 2020, 40, 74.

15. Dhar, M.L.; Dhar, M.M.; Dhawan, B.N.; Mehrota, B.N.; Ray, C. Indian J. Exp. Biol., 1968, 6, 232-247.

16. Govindaraj. S.; Rajangam, U. J. Complement. Altern. Med. Res., 2017, 3, 1-13.

17. Ankita, S.; Tribhuwan, S.; Rekha, V. Int. Res. J. Pharm., 2015, 6, 269-272.

18. Marrez, D.A.; Naguib, Md.M.; Sultan, Y.Y.; Higazy, A.M. Heliyon., 2019, 5, e01404.https:// doi.org/10.1016/j.heliyon.2019.e01404.

19. Konovalova, O.; Gergel, E.; Herhel, V. The Pharma Innovation-J., 2013, 2, 7-12.

20. Su-Jin, K.; Won-Seok, Ch.; Sung-Soo, K.; Seong-Gyu, Ko.; Jae-Young, Um. Phytotherapy Res., 2011, 25, 1537-1546.

21. Gopinath, S.; Saktthidevi, G.; Muthu kumar aswamy, S.; Mohan, V.R. J. Curr. Chemical. Pharma. Sci., 2013, 3, 6-15.

22. Abubakar, M.N.; Majinda, R.R.T. Medicines, 2016, 3, 1-9. doi:10.3390/medicines3010003. 